\title{
Analysis of External Diaphragm Beam Column Connection of Concrete Filled Steel Tube (CFST) Using ANSYS
}

\author{
S. M. Suresh Kumar ${ }^{1}$ and M. Manivannan ${ }^{2}$ \\ \{mailbox.sureshkumar@gmail.com ${ }^{1}$, mmv.civil@psgtech.ac.in ${ }^{2}$ \} \\ ${ }^{1}$ Former Post Graduate student, ${ }^{2}$ Associate Professor,Department of Civil Engineering, PSG College of \\ Technology, Coimbatore, India
}

\begin{abstract}
Concrete Filled Steel Tube (CFST) is a steel-concrete composite structure that combines advantages of both steel and concrete. The strength of CFST is always greater than the sum of the strength of steel and that of concrete. In terms of seismic response, the CFST system's linkages are crucial.Different connection methodologies are tested and used around the globe. This paper uses FEA analysis with the ANSYS software package to try to understand the non-linear behavior of an external diaphragm Concrete filled Steel Tube (CFST) Beam Column connection.The model is created based on the existing experimental studies on the material. The results are validated by existing experimental results. This paper considers studies external diaphragm connection as it is one of the most widely used connection in CFST due to its ease in construction. To acquire the response of the model in the non-linear domain, it is subjected to quasi-static cyclic loading.
\end{abstract}

Keywords: CFST beam column connection, non-linear, quasi-static cyclic loading, diaphragm connection, ANSYS

\section{Introduction}

Rapid improvement in global infrastructures, high demand in urban spaces and expanding economical activities demands construction of tall structures even at places of adverse conditions like earthquake prone, heavy wind prone, low bearing capacity of soil etc. The construction period of such structures should also be as minimum as possible. A conventional reinforced concrete structure requires large section of columns which in turn increase cost, construction period and reduces utilizable space. Conventional $\mathrm{RC}$ structures also tend to be ductile and requires large amount of transverse reinforcements. Steel structures are used in construction of such tall structures with heavy structural demands. The construction methodologies have evolved to apply concrete steel composite structures which have the advantages of both steel and concrete.

Concrete Filled Steel Tube (CFST) system is concrete steel composite in which reinforced or unreinforced concrete is placed inside a circular or rectangular hollow steel section. It has higher 
strength compared to individual strength of concrete and hollow steel section combined. This is due to the fact that either component counters the failure of the other component. Compressive strength of concrete is enhanced by the confining pressure contributed by the steel section. The infill concrete prevents the steel portion from buckling inward.

The steel, being the element with higher strength, is placed at the furthest from the centroid of the member. This increases the flexural capacity of the member. The steel section also acts as a formwork for the infill concrete thereby reducing the cost and duration of construction. The outer steel protects the concrete from abrasive and impact forces. The CFST system generally has high ductility and energy dissipation.

The CFST system has been used often in developed countries like US, Japan, Canada etc. because it combines the merits of both concrete and steel. Some of the reasons for implementation of CFST systems are.

CFST has higher compression and flexural capacity.

Higher rigidity compared to conventional structures.

Infill concrete can be utilized in sections with thin steel walls to prevent buckling of the steel section on a local level.

Excellent fire resistance and energy dissipation.

Requires low man power due to absence of formwork

Facilitates speedy and quality construction

Several researches are underway to study the behavior of CFST systems. Connection performance determines the ductility of the structure and thereby the suitability to seismic prone zones. Several types of connections are modeled and tested. In this paper, one of the important and widely used connection types will be analyzed namely external diaphragm connection using ANSYS 16.0 workbench.

\section{Finite Element Model(FEM)}

\subsection{Model Geometry}

Two models of exterior CFST column with external and through connections are modeled. For the external diaphragm CFST connection, circular steel section of diameter $355.6 \mathrm{~mm}$ and of thickness of $6.4 \mathrm{~mm}$ is joined with a W $14 \times 38$ wide flange beam section.External diaphragm plates are mounted to both the top as well as bottom flanges of the beam to make the connection, as shown in Fig.1.Stiffeners are provided at the point of application of load. The geometry of the models is adopted from the experiments conducted by S. P. Schneider et.al. 

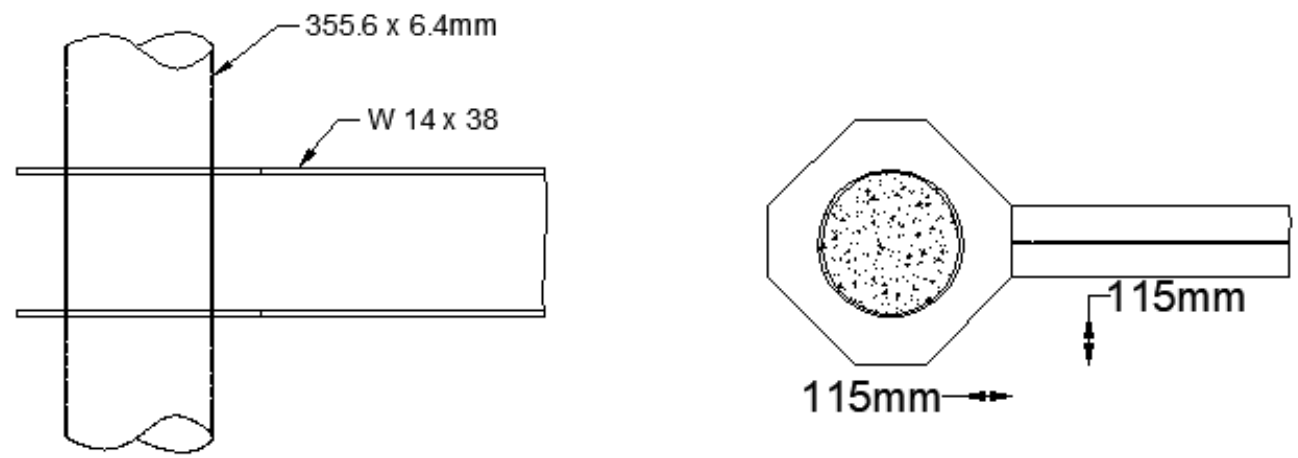

Fig.1 Section detail of external diaphragm connection

\subsection{Material modeling}

\subsubsection{Concrete}

The confined concrete has greater ductility and strengthbecause of the confinement effect generated by the surrounding steel.A multi-linear isotropic hardening model based on Liang et al's general stress strain curve is used to model the concrete element.

The stress-strain curve is divided into three sections. The Mander et al proposed the equation that can be used to model the first region.

$$
\begin{aligned}
& \sigma_{\mathrm{c}}=\frac{\mathrm{f}^{\prime}{ }_{\mathrm{cc}} \lambda\left(\varepsilon_{\mathrm{c}} / \varepsilon^{\prime}{ }_{\mathrm{cc}}\right)}{\lambda-1+\left(\varepsilon_{\mathrm{c}} / \varepsilon_{\mathrm{cc}}^{\prime}\right)^{\lambda}} \\
& \lambda=\frac{E_{\mathrm{c}}}{E_{\mathrm{c}}-\left(\frac{\mathrm{f}^{\prime} \mathrm{cc}}{\varepsilon_{\mathrm{cc}}^{\prime}}\right)}
\end{aligned}
$$

Where $\sigma_{\mathrm{c}}$ is the stress for the strains below $\varepsilon^{\prime}{ }_{\mathrm{cc}}$ which is the strain which is corresponding to the compressive strength of confined concretef ${ }^{\prime}{ }_{c c}$. ACI formula can be used to calculate the elastic modulus of constrained concrete.

$$
\mathrm{E}_{\mathrm{c}}=3320 \sqrt{\gamma_{\mathrm{c}} \mathrm{f}_{\mathrm{c}}{ }^{\prime}}+6900(\mathrm{MPa})
$$

Where $\gamma_{c}$ is the strength reduction factor, which is computed, based on the inner core concrete diameter Dc as described by Liang.

$$
\gamma_{c}=1.85 \mathrm{D}_{\mathrm{c}}^{-0.135}\left(0.85 \leq \gamma_{\mathrm{c}} \leq 1.0\right)
$$

The constrained compressive strength of concrete and related strain are determined by 


$$
\begin{gathered}
\mathrm{f}_{\mathrm{cc}}^{\prime}=\gamma_{\mathrm{c}} \mathrm{f}_{\mathrm{c}}^{\prime}+\mathrm{k}_{1} \mathrm{f}_{\mathrm{rp}} \\
\varepsilon_{\mathrm{cc}}^{\prime}=\varepsilon_{\mathrm{c}}^{\prime}\left(1+\mathrm{k}_{2} \frac{\mathrm{f}_{\mathrm{rp}}}{\gamma_{\mathrm{c}} \mathrm{f}_{\mathrm{c}}^{\prime}}\right)
\end{gathered}
$$

According to research of Richart et al, k1 and k2 are confinement effect constants that are supposed to be 4.1 and 20.5 , respectively. The strain $\varepsilon_{\mathrm{c}}$ correcponding to f'cc can be calculated as

$$
\begin{aligned}
\varepsilon_{\mathrm{c}}^{\prime}=\left\{0.002 \text { for } \gamma_{\mathrm{c}} \mathrm{f}_{\mathrm{c}}^{\prime}\right. & \leq 28(\mathrm{MPa}) 0.002+\frac{\gamma_{\mathrm{c}} \mathrm{f}_{\mathrm{c}}^{\prime}-28}{54000} \text { for } 28<\gamma_{\mathrm{c}} \mathrm{f}_{\mathrm{c}}^{\prime} \leq 82(\mathrm{MPa}) 0.003 \text { for } \gamma_{\mathrm{c}} \mathrm{f}_{\mathrm{c}}^{\prime} \\
> & 82(\mathrm{MPa})
\end{aligned}
$$

Where frprepresents the confining pressureprovided by steel tube on the concrete..It is determined using the $\mathrm{D} / \mathrm{t}$ ratio

$$
\mathrm{f}_{\mathrm{rp}}=\left\{0.7\left(v_{\mathrm{e}}-v_{\mathrm{s}}\right) \frac{2 \mathrm{t}}{\mathrm{D}-2 \mathrm{t}} \mathrm{f}_{\mathrm{sy}} \text { for } \frac{\mathrm{D}}{\mathrm{t}} \leq 47\left(0.006241-0.0000357 \frac{\mathrm{D}}{\mathrm{t}}\right) \mathrm{f}_{\mathrm{sy}} \text { for } 47<\frac{\mathrm{D}}{\mathrm{t}} \leq 150\right.
$$

$v_{\mathrm{s}}$ and $v_{\mathrm{e}}$ are respectively are the Poisson's ratios of an empty steel tube and an in filled steel tube. The steel tube with no infill has a Poisson's ratio of 0.5 , as suggested.

$$
\begin{aligned}
& v_{\mathrm{e}}=0.2312+0.3582 v_{\mathrm{e}}^{\prime}-0.1524\left(\frac{\mathrm{f}_{\mathrm{y}}}{\mathrm{f}_{\mathrm{sy}}}\right)+4.843 v_{\mathrm{e}}\left(\frac{\mathrm{f}_{\mathrm{y}}}{\mathrm{f}_{\text {sy }}}\right)-9.169\left(\frac{\mathrm{f}_{\mathrm{y}}}{\mathrm{f}_{\text {sy }}}\right)^{2} \\
& v_{\mathrm{e}}^{\prime}=0.881 \times 10^{-6}\left(\frac{\mathrm{D}}{\mathrm{t}}\right)^{3}-2.58 \times 10^{-4}\left(\frac{\mathrm{D}}{\mathrm{t}}\right)^{2}+1.953 \times 10^{-2}\left(\frac{\mathrm{D}}{\mathrm{t}}\right)+0.4011
\end{aligned}
$$

The second part of the curve is formed by a sloped line from $\mathrm{f}^{\prime}{ }_{\mathrm{cc}}$ to $\beta_{\mathrm{c}} \mathrm{f}^{\prime}{ }_{\mathrm{cc}}$ and the curve becomes a straight line parallel to the $\mathrm{x}$ axis. $\varepsilon_{\mathrm{cu}}$ is taken as 0.02 .

$$
\sigma_{\mathrm{c}}=\left\{\beta_{\mathrm{c}} \mathrm{f}_{\mathrm{cc}}^{\prime}+\left(\frac{\varepsilon_{\mathrm{cu}}-\varepsilon}{\varepsilon_{\mathrm{cu}}-\varepsilon_{\mathrm{cc}}^{\prime}}\right) \text { for } \varepsilon_{\mathrm{cc}}^{\prime}<\varepsilon \leq \varepsilon_{\mathrm{cu}} \beta_{\mathrm{c}} \mathrm{f}_{\mathrm{cc}}^{\prime} \text { for } \varepsilon>\varepsilon_{\mathrm{cu}}\right.
$$
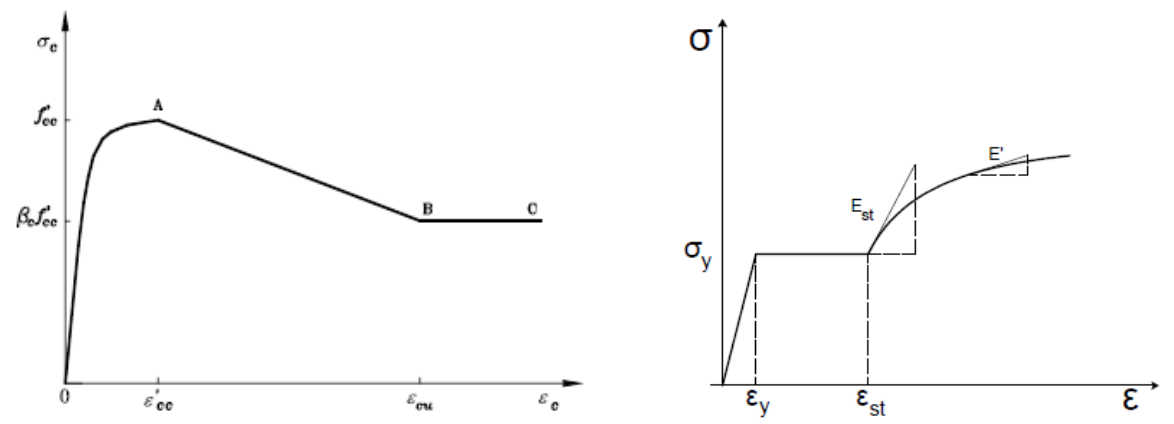

Fig 2 Stressstrain curve for (a) plain concrete and (b) steel 


\subsubsection{Steel}

A multi-linear kinematic hardening model is used to simulate the steel's non-linear behavior. The uniaxial stress-strain curve for the steel is shown in figure $2 b$.

$$
\begin{gathered}
\mathrm{E}^{\prime}=\frac{\mathrm{d} \sigma}{\mathrm{d} \varepsilon}=\mathrm{E}_{\mathrm{st}} \cdot \mathrm{e}^{-\xi\left(\frac{\varepsilon}{\varepsilon_{\mathrm{y}}}-\frac{\varepsilon_{\mathrm{st}}}{\varepsilon_{\mathrm{y}}}\right)} \\
\frac{\sigma}{\sigma_{\mathrm{y}}}=\frac{1}{\xi} \frac{\mathrm{E}_{\mathrm{st}}}{\mathrm{E}}\left\{1-\mathrm{e}^{-\xi\left(\frac{\varepsilon}{\varepsilon_{\mathrm{y}}}-\frac{\varepsilon_{\mathrm{st}}}{\varepsilon_{\mathrm{y}}}\right)}\right\}+1 \quad \varepsilon \geq \varepsilon_{\mathrm{st}}
\end{gathered}
$$

A hardening strain $\varepsilon_{\text {st }}$ of 0.005 is used.. The steel material assumedhere is SM490.

\begin{tabular}{|c|c|c|c|}
\hline Material & $\xi$ & $\frac{E}{E_{s t}}$ & $\frac{\varepsilon_{s t}}{\varepsilon_{y}}$ \\
\hline SM490 & 0.06 & 30 & 7 \\
\hline
\end{tabular}

Table .1 Parameters for stress strain equation

\begin{tabular}{|c|c|c|c|}
\hline & $\begin{array}{c}\text { Yield } \\
\text { Strength } \\
\left(\mathrm{f}_{\mathrm{y}}\right), \mathrm{MPa}\end{array}$ & $\begin{array}{c}\text { Young's } \\
\text { Modulus } \\
\left(\mathrm{E}_{\mathrm{s}}\right) \\
\mathrm{GPa}\end{array}$ & $\begin{array}{c}\text { Ultimate } \\
\text { Strength }\left(\mathrm{f}_{\mathrm{u}}\right) \mathrm{MPa}\end{array}$ \\
\hline Steel pipe & 396.5 & 222 & 540 \\
Beam & 358.5 & 221 & 490 \\
Connection Stub & 271.7 & 217 & 415 \\
\hline
\end{tabular}

Table.2Properties of Steel

\subsubsection{The Concrete Steel Interface}

The interface of between concreteand steel is important to replicate the confinement effect of the CFST system. It is modeled with coulomb friction model. The friction coefficient between the surfaces is assumed to be 0.6 .

\section{Applied Displacement and Loading}

To reproduce the test configuration depicted in fig.3, boundary conditions are implemented in the model. A roller support is applied to the top of the columnarresting movement in $\mathrm{X}$ and $\mathrm{Y}$ directions. The bottom of the column is provided with a hinge support restricting motion in all direction. A constant axial force of $580 \mathrm{KN}$ is applied onthe top of the column. The load is applied 
on the loading plate at the end of the beam. As per the specification of Earthquake Testing Methods for Earthquake Resistant Buildings (JGJ 101-1996, 1996),Initially force is applied in cycles and reversed until yielding occurs. When yielding occurs the beam is subjected to cycles of displacement.

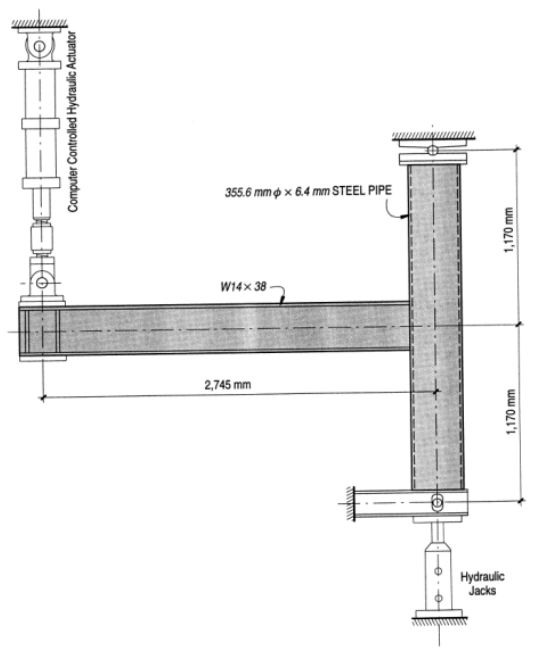

Fig.3. Test setup

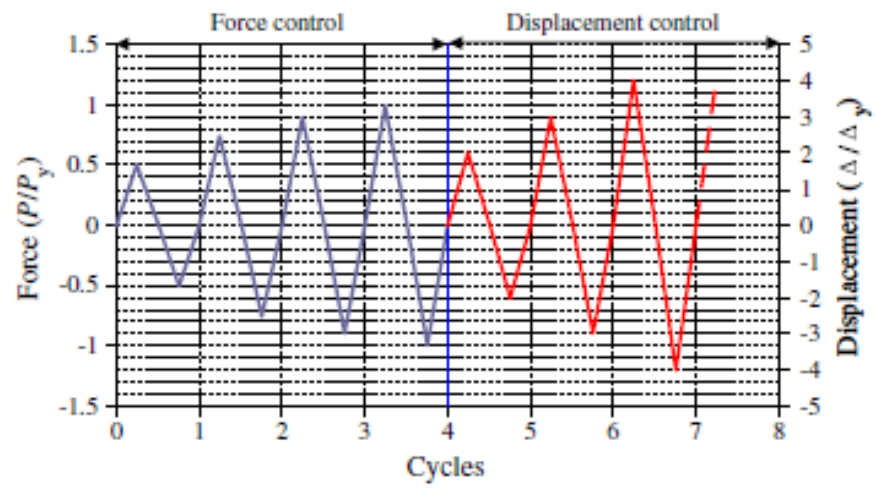

Fig 4 Loading pattern

\section{Determination of Yield Load}

A linearly increasing load is supplied to the end of the beam until yielding occurs..The load deflection curve for the setup was formed as shown in fig.5. The load Py at which yielding occurred and the corresponding deflection $\Delta \mathrm{y}$ is noted to create the loading cycle. Yield load is 
found as $136 \mathrm{KN}$ by the change in the slope of the curve. The load is applied in cycles in force controlled region and continued with displacement controlled cycles of magnitude $0.5 \Delta y$, $\Delta \mathrm{y}, 1.5 \Delta \mathrm{y}$ until failure.

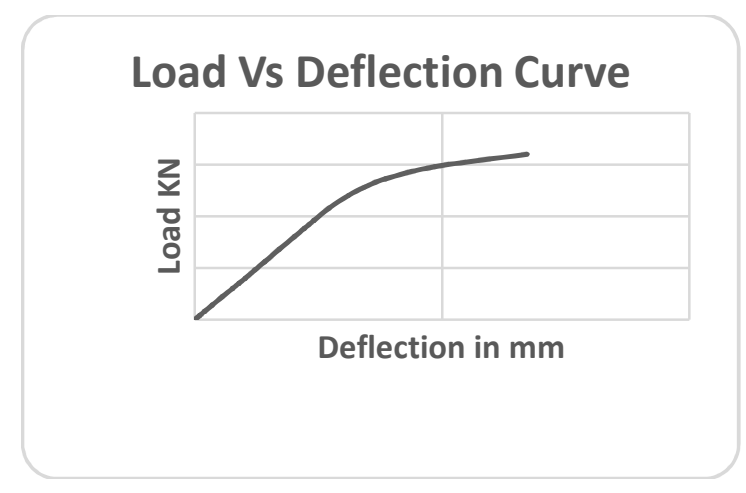

Fig 5 LoadDeflection curve

\section{Discussion and Results}

The yielding and failure of the elements are found by comparison of Equivalent Von Misesstress to the yield strength and ultimate strength.In the first cycle, the stresses were within the yield strength. The top and bottom of the diaphragm experienced localized stresses at the junction. The stresses in the setup are shown in fig 6 . The stress at second and third positive peaks respectively is shown in fig. 7 and fig. 8

In the second positive cycle, the stress propagates increases along the length of the beam the yielding starts to occur at the diaphragm connection. The junction of the diaphragm and the connection web start to yield. 

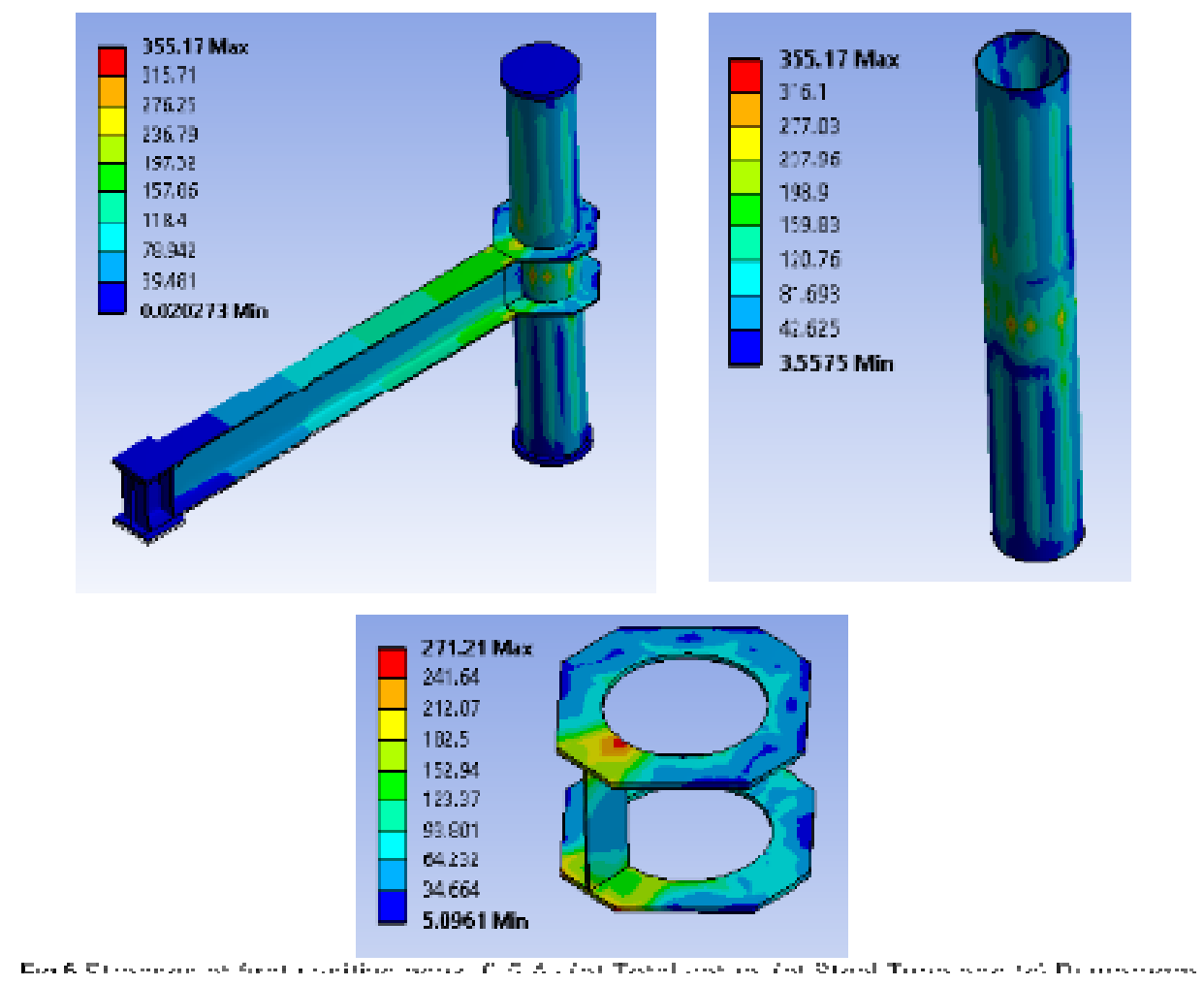

In the third cycle, the stresses at the diaphragm almost reach the ultimate strength. The stresses in the beam and tube also reach yield stress.Hysteresis loop of the setup is shown in fig 9. 

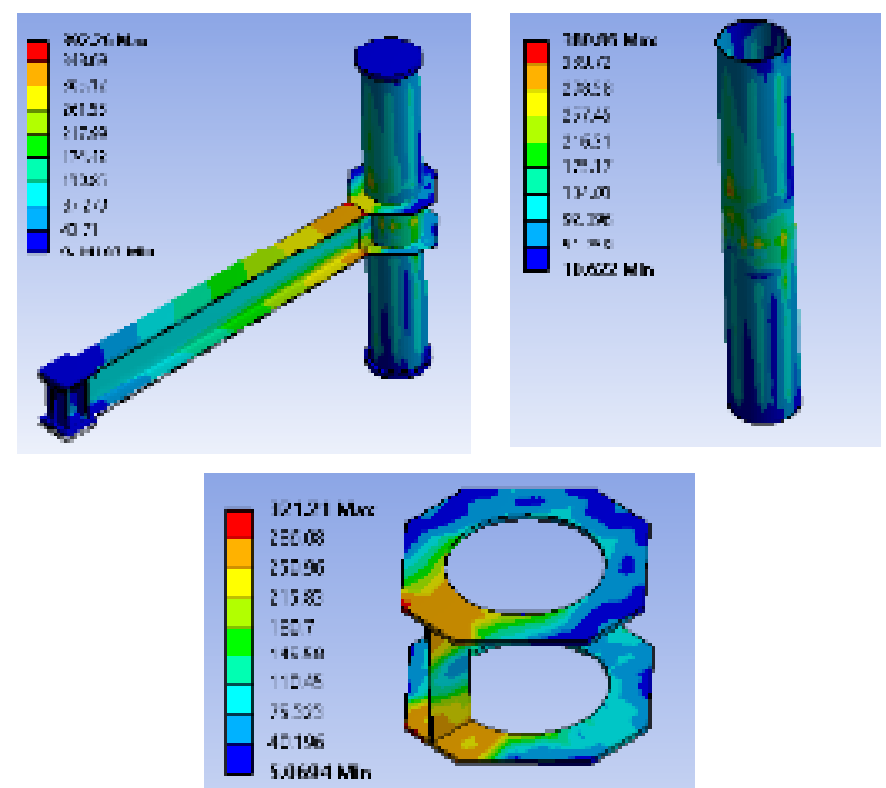

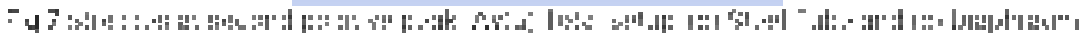
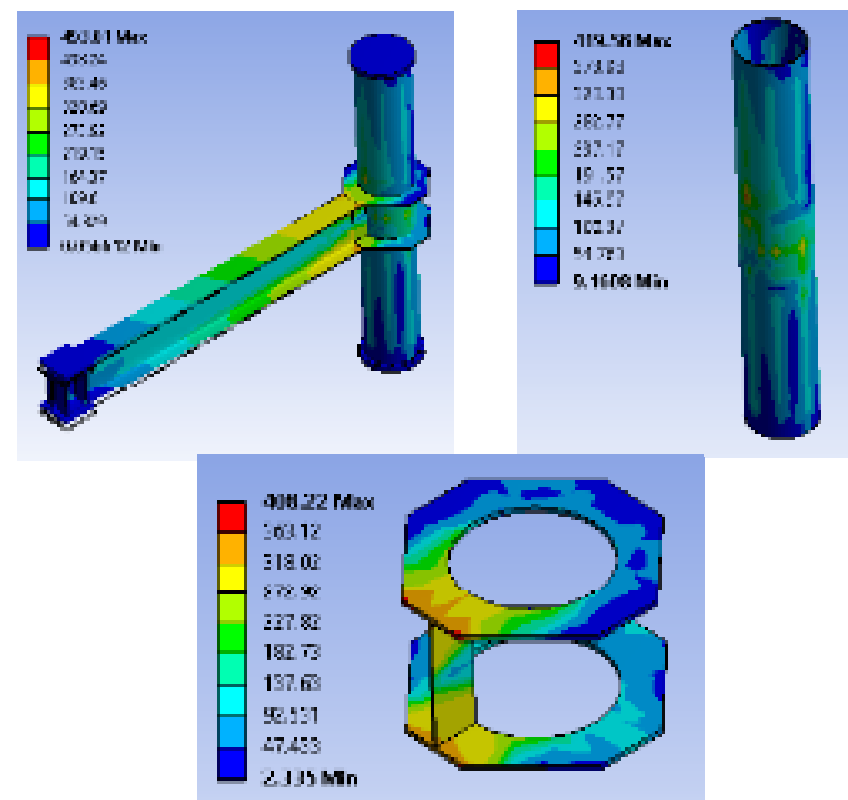

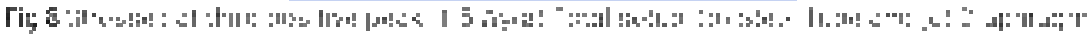




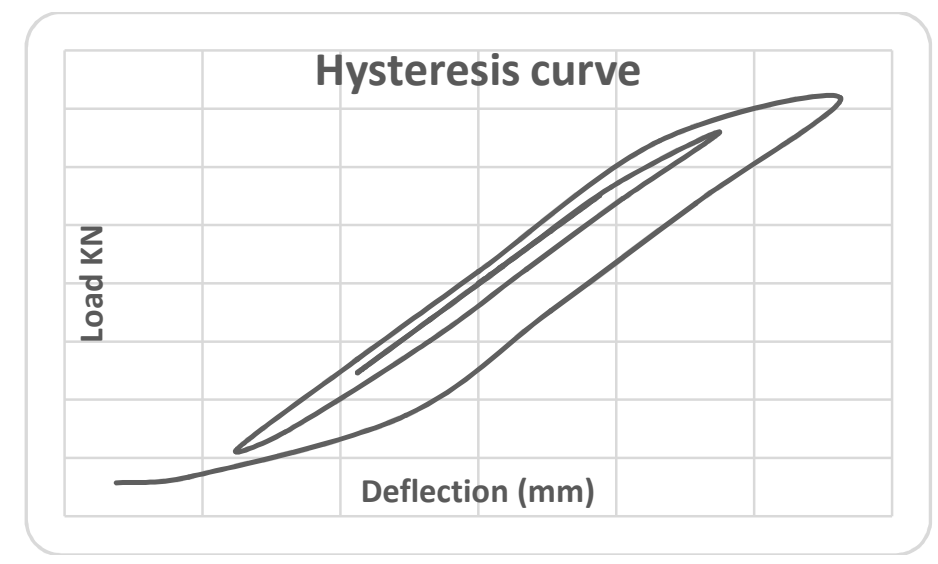

Fig 9 Hysteresis curve

\section{Conclusion}

The FEA model represents the failure of the external diaphragm connection. Low area of hysteresis loop dictates low energy dissipation. Further design considerations can be made on the understanding from this study.

\section{References}

[1]. AtorodAzizinamini, and Stephen P. Schneider, "Moment Connections to Circular Concrete-Filled Steel Tube Columns”, Journal Of Structural Engineering ASCE 2004,213-222.

[2]. J W Park, S M Kang and S C Yang (2005) "Experimental studies of wide flange beam to square concrete filled tube column joints with stiffening plates around the column" Journal of Structural Engineering, Vol. 131, No. 12, December 1.

[3]. Stephen P. Schneider, Yousef M. Alostaz. "Experimental Behavior of Connections to Concrete-Filled Steel Tubes", Journal of Constructional Steel Research, Vol. 45, No. 3, pp. 321-352, 1998

[4]. Qing Quan Liang, Sam Fragomeni. "Nonlinear analysis of circular concrete-filled steel tubular short columns under axial loading."Journal of Constructional Steel Research, Vol.65 (2009) 2186-2196.

[5]. Mander JB, Priestly MNJ, Park R. "Theoretical stress strain model for confined oncrete. Journal of Structural Engineering,” ASCE 1988; 114(8):1804-1826.

[6]. R. Goplalakrishnan, A. Mohan, L. Ponrajsankar, D. S. Vijayan, "Characterisation On Toughness Property of Self- Compacting Fibre Reinforced Concrete", Journal of Environmental Protection and Ecology 21, No 6, 2153-2163 (2020).

[7]. D. S. Vijayan, A. Mohan, J. J. Daniel, V. Gokulnath, B. Saravanan, and P. D. Kumar, "Experimental Investigation on the Ecofriendly External Wrapping of Glass Fiber Reinforced Polymer in Concrete Columns," vol. 2021, 2021.

[8]. Liang QQ. "Performance-based analysis of concrete-filled steel tubular beam_columns. Part I: Theory and algorithms." Journal of Constructional Steel Research, 2009;65(2):363-73 
[9]. Richart FE, Brandtzaeg A, Brown RL. "A study of the failure of concrete under combined compressive stresses.” Bull. 185. Champaign (III): University of Illinois, Engineering Experimental Station; 1928.

[10]. Daxu Zhang, ShengbinGao, JinghaiGon "Seismic behaviour of steel beam to circular CFST column assemblies with external diaphragms" Journal of Constructional Steel Research,Vol.76 (2012) 155-166 